\title{
The Value of Demand Information in Omni-Channel Grocery Retailing
}

\author{
Chokdee Siawsolit \\ Claremont Graduate University \\ chokdee.siawsolit@cgu.edu
}

\author{
Gary Gaukler \\ Claremont Graduate University \\ gary.gaukler@cgu.edu
}

\begin{abstract}
As e-commerce reaches one of the last strongholds of traditional fulfillment, how can grocers leverage the omni-channel trend and stay competitive in today's changing market landscape? To improve operating outcomes and address food waste concerns, this study investigates various scenarios in which the grocery retailer accepts online orders in advance. We examine the value of advance demand information through a Markov Decision Process-based model, in terms of changes to expected profits, outdating, freshness, and several inventory and service performance metrics.

Our results indicate that when the demand lead time is longer than the replenishment lead time, close to $20 \%$ safety stock reduction on average can be achieved, leading to a $15 \%$ decrease in product deterioration and $26 \%$ less outdating. In some cases, we also find that it is possible to profitably offer discounted prices in exchange for the customer's future demand information.
\end{abstract}

\section{Introduction}

The fridge is nearly empty. Where do we go to stock up on perishable food items? According to data from the Bureau of Labor Statistics, on an average day 1 out of 7 American adults visit the grocery store [1]. The US grocery industry is highly consolidated and generates $\$ 683$ Billion in sales [2]. However, despite a growing number of stock-keeping units (average 38,900 per store), profit margins remain extremely slim [3].

In contrast to other retail sectors, a distinctive challenge faced by grocers is in the handling of inventory with very limited shelf lives. Due to biological decay and microbial growth, perishable food items deteriorate over time. When freshness drops below a certain quality threshold, the product loses salability and gets marked down or discarded. We call this 'outdating'.

It has been estimated that outdating accounts for a loss of $\$ 2,300$ per store per day [4]. Further complicating the problem, millennial shoppers have practically declared war on preservatives. Without chemical agents to prevent deterioration, healthier foods often have lower and less predictable shelf lives [5].
The costs associated with having inventory on hand expire presents a major obstacle in maintaining adequate service level while minimizing operating costs. As a result of demand variability, ordering too much leads to outdating of perished products, and ordering too little translates to more lost sales; an unpleasant experience potentially degrading the customer's loyalty.

The economic impacts from food waste resonate both upstream to producers, and down all the way to consumers. Many grocers have turned to technological solutions to combat this issue, including RFID and GPS tracking of replenishments [6]. Others have explored using blockchain technology to track shipment data logs, such as place of origin or temperature variations during transport [7]. These new developments greatly improve the visibility of supply-side information; allowing retailers to accurately predict the remaining shelf lives of products at the time they arrive at the store.

Likewise, more consumers than ever have adopted the use of smart devices. This has led to the emergence of additional internet retailing and omni-channel experiences through flexible shopping and fulfilment platforms (e.g. Walmart's order online, pickup in-store). Across the nation, brick and mortar grocery retailers are currently finding themselves in a transition phase toward online commerce. What are the implications on perishable inventory management?

While online grocery accounts for just over $4 \%$ of total grocery sales, various estimates suggest the figure is growing at an accelerated rate [8]. More importantly, transactions data collected from 200 stores over a 1 month period found that $85 \%$ of online grocery orders included at least one produce item; and 66\% contained meat, seafood or deli products [9]. Big or small, online grocery is encroaching on traditional grocers' territories. Are there characteristics currently present in multichannel retailing that may help physical grocers deal with perishables more effectively?

Due to shipping times, online shoppers have become accustomed to varying levels of delay between the time of placing orders and fulfillment. A survey of over 30,000 respondents reported $28 \%$ have had online grocery delivered to home at some point [10]. Could the time gap between order placement and order fulfillment be useful in deciding the daily replenishment quantities? 
What if omni-channel is actually not a burden, but part of a solution to managing perishables? Specifically, our research attempts to understand the consequences of accepting advance online grocery orders through providing customers with options to place orders in advance. Using decision analytics, we assume the perspective of a retailer facing stochastic end consumer demand, as well as costs associated with outdating products, losing sales, and holding inventory.

The objectives here are to reduce outdating and improve long run expected profits for perishable foods with short shelf lives; such as soft-skinned fruits, leafy vegetables, or fresh seafood. By having better access to supply and demand information, and deciding the optimal amount of products to stock, could retailers reduce waste from outdating, increase margins, or even offer discount to customers?

\section{Literature review}

From perishables supply chain to decision science and e-commerce, this work brings together multiple streams of literature. To gain a better understanding of later discussions, the following three sub-sections briefly review relevant past contributions and recent advances in decision analytics of perishables retailing.

\subsection{Perishable inventory management}

The literature review by Karaesmen et al. (2011) references almost 200 articles and book chapters on the topic of managing perishables [11]. They classify the literature into fixed and random life time, as well as periodic and continuous review of inventory control policy. Research focusing on random life time, as in our case here, can mostly be traced back to Nahmias (1977) [12]. Nahmias (1982) further provides a review of the ground work on determining suitable ordering policies for inventory subject to continuous decay [13].

Later, Williams and Patuwo (1999) derive the equations to decide order quantities for a product with a useful lifetime of two periods, and indicate that order quantity is a function of the lead time and the quantity of goods on-hand and in arrival [14]. Minner and Transchel (2010) propose a method to determine dynamic order quantities for perishable products with limited shelf-life, positive lead time, along with FIFO issuing policy. They also illustrate the superiority of this method over common order-up-to policies [15].

More recently, Bakker et al. (2012) show an updated review of the advances made in the field of perishable inventory control and classify contributions by system characteristics such as pricing discounts, backordering or lost sales [16]. Overall, there appears to be a clear interest in reducing not only costs, but also to integrate production and distribution planning of perishable products with considerations given to other business aspects, including product quality and waste reduction (Amorim et al. 2012; Pahl and Voß, 2014) [17, 18].

\subsection{Time and temperature monitoring}

The value proposed here is based partly on the information obtained from time and temperature history (TTH). Taoukis et al. (1999) explore various conditions that perishable products are exposed to during shipment [19]. Most fruits and vegetables first enter the supply chain after harvest at ambient temperature. They are then delivered to regional distribution centers and enter a temperature-controlled chain. External factors such as distance, time spent, or weather could all cause variations to the amount of remaining life of products. Nunes et al. (2005) report that temperature is the main characteristic of distribution environment to cause the greatest negative impact on shelf life of perishables [20].

An application of RFID technology to perishables tracking can be found, for instance, in Chande et al. (2005); where an integrated framework for inventory management and dynamic pricing in a discrete time setting is described in detail [21]. In addition, Sahin et al. (2007) provide a number of potential benefits that can be expected from the use of TTH, including information on product freshness and remaining shelf lives, as well as directions for quantitative models that can be developed to assess these benefits [22].

Many studies suggest replacing traditional expiry dates with some form of remaining-shelf-life indicator based on TTH data. Grunow and Piramuthu (2013) explore the utility of sensor-enabled, item-level tags in a highly perishable food supply chain from several perspectives including the distributor, retailer and consumer [23]. Herbon et al. (2014) also propose many advantages of implementing TTH tracking to reduce the risk of selling subpar products to customers [24].

\subsection{Value of information}

Sahin and Robinson (2002), as well as Huang et al. (2003), provide a broad overview of literature on value of information (VOI) for inventory management [25, 26]. Publications concerning the value of 'supply-side' information (lead time, product life, etc.) for managing perishables can be found as early as Pierskalla and Roach (1972); where quantitative results support policies that issue the oldest inventory units to satisfy demand [27]. Apart from the inventory issuing policy, the store's daily replenishment decision is of great interest to our target of reducing outdating at retail level. 
The mathematical framework of Markov Decision Processes (see, e.g., Puterman (1994)) allows for an insightful investigation of the problem in states of inventory where the grocer takes action periodically through placing orders [28]. Aggoun et al. (1999) later establish an integer-valued model for perishables along with various parameter estimators to find an optimal replenishment schedule [29]. Kouki et al. (2010) and (2015) further describe the use of transition probabilities and steady-state properties to predict the effects of life time variability on cost performance; taking into account lost sale and outdating costs [30, 31].

Currently, there are considerable research activities in assessing the value of supply information. Studies on VOI gained through implementing RFID in perishable inventory management by Ketzenberg et al. (2015) and dynamic expiration dates by Gaukler et al. (2017) report up to $43.2 \%$ and $41.2 \%$, respectively, in cost reductions on average with a 1 day lead time [32,33]. Chua et al. (2017) explore optimal discounting and replenishment policies for products with mean shelf lives of 2 days, and found that discounts are best offered when inventory units are below a certain age class [34]. Adenso-Diaz et al. (2017) and Buisman et al. (2017) also present studies on using dynamically-set shelf life and offering dynamic pricing based on remaining life [35, 36]. Most recently, Ketzenberg et al. (2018) derive inventory control and expiration dating policies where a hazard cost of selling perished units is considered, and provide insights on the link between perishability and inventory cost [37].

Additionally, much work has been done to study and quantify the value of 'demand-side' information. The seminal paper by Hariharan and Zipkin (1995) reveals how advance orders can improve an inventory system in the same way that supply lead times degrade it; coining the term 'demand lead time' [38]. Gallego and Özer (2001), as well as Karaesmen et al. (2004), later investigate inventory systems that incorporate advance demand information (ADI). Both studies show that applying the appropriate replenishment policy can lead to significant cost reductions, and that the impact on cost performance is dependent on both demand lead time and supply lead time [39, 40]. Wang and Toktay (2008) further extend the work of Gallego and Özer by allowing flexible demand lead times, and suggest that increasing the demand lead time is more cost effective than reducing the supply lead time by the same amount [41].

Numerous other contributions can be found on the topic of ADI, however, those that deal with perishable inventory are less common at the moment. Thus, this paper aims to complement the value of ADI stream of literature; with a distinctive focus on freshnessconstrained products. Siawsolit et al. (2018) closely resemble our starting point in terms of modeling and the grocery retail setting [42]. It is from here that we continue to expand the ADI literature. The novelty of this work includes a quantitative study on accepting online grocery orders in advance, the benefits of extending the demand lead time for perishable products, and the feasibility of offering a discount to customers.

\section{Setting}

Consumers have been seeing the rise of multichannel service offerings such as 'order online today pick up in-store tomorrow', or 'free 2-day shipping on orders above $\$ 50$ '. Younger millennials are particularly more inclined to use these services, with up to $15 \%$ saying they are willing to pay a premium, compared to $4 \%$ of older boomers [43]. We investigate a setting in which the grocer allows customers to purchase products by offering two basic fulfillment options: (1) traditional fulfillment: the customer comes to the store as usual and selects products from the shelves; (2) advance online ordering: the customer places an order online 1 or 2 days ahead of time and either picks up the items from the store, or has the store deliver the items.

With advance ordering, a store employee prepares the pickup order before the customer's designated arrival time. Certain Walmarts in China have already set aside convenience-store sized areas for workers to fulfill this role. For a more sophisticated approach, advance orders can also be prepared at a distribution warehouse level through automated robot handling as implemented by Ocado in the United Kingdom [44].

In essence, online ordering allows the store to collect ADI, because demand occurrence and fulfillment do not coincide. The goal here is to reduce safety stock levels; thereby also reducing the frequency of outdating events. The research questions include: can ADI substantially improve inventory performance, and if so, what are the implications on food waste? Should the store entice more of its customers to place order in advance, perhaps by offering a discount on prices?

It is not clear at this point, though, how the incentives would correlate with the customer's willingness to place advance orders. Therefore, our study explores the implications of offering a specified fulfillment option with some response rate (for example: $20 \%$ of demands are pick up next day), in comparison to the base case where all demands must be immediately filled (i.e., traditional fulfillment). The setting is analyzed through an inventory optimization model based on Markov Decision Processes (MDP). Overall, we are interested in finding out if stores could afford to offer discounts at all. Given insights into future shelf lives and ADI, how will the scenarios outlined above affect expected profits, outdating, freshness, and various inventory metrics? Can sustainability be profitable at the same time here? 


\section{Modeling}

The study is performed through the use of a profitmaximization MDP, which allows us to view the system as being in one of a number of possible states, $S$, of inventory status. In each respective state, the grocer is presented with a choice of how much to order, $q$.

The store places an order once a day and receives replenishment from suppliers with a constant lead time of 1 day. We assume the supplier can provide accurate estimates as to when a given lot of goods will perish based on time \& temperature history (TTH) from RFID tracking (see, for instance, Gaukler et al. 2017 for a detailed modeling treatment of TTH data for perishables management) [33]. Specifically, once products are received, the remaining shelf life (referred to as age class $a$ ) becomes known and is described by a discrete probability distribution $\varphi(a)$ with a maximum length of $M$ days. Each passing day the particular lot of goods remains in inventory, its age class reduces by one. Once $a$ reaches 0 , the lot is presumed to drop below the quality threshold and is outdated by the grocer.

For tractability, we assume there are no shortages in supply, and a product retains constant utility while its remaining shelf life is greater than 0 . All units received in the same lot of replenishment will expire at the same time due to undergoing the same environmental conditions during transport. Inventory units are sold by first-to-expire, first-out policy (FEFO) based on information available through TTH monitoring. Let $i_{a}$ denote the amount of inventory on hand having age class a. For example, if $i_{a}$ could be 0 or 1 , and $M=2$, we have 4 possible inventory states; namely $\{0,0\},\{1,0\},\{0,1\}$ and $\{1,1\}$. The probability of moving from one state $(S)$ to another $\left(S^{\prime}\right)$ by taking action $(q)$ is represented by $P_{q}\left(S, S^{\prime}\right)$, or $P_{q}\left(\left\{i_{1}, \ldots, i_{M}\right\},\left\{i_{1}^{\prime}, \ldots, i_{M}^{\prime}\right\}\right)$.

Demand is modeled as discrete, stochastic, and stationary over time. When advance ordering is allowed, incoming demand is split into independent streams of immediate demand and advance orders (pick up 1 or 2 days later). Immediate demand is denoted by $d_{\text {imm }}$, and follows a probability mass function $\phi\left(d_{i m m}\right)$. Advance demand, $d_{a d v}$, is accounted for through backlogging, based on the distribution $\Theta\left(d_{a d v}\right)$. All backlogged demands are given priority fulfillment once inventory arrives.

The order of events each day consists of: (i) receive replenishment from an order made the previous day, (ii) allocate the replenishment into specified age categories and place an order if necessary, (iii) face incoming demand throughout the day, and (iv) reduce age classes of all unsold inventory at the end of the day by 1 and outdate any perished units from inventory.
We introduce an additional state variable for backlogs, denoted $b$, to keep track of the amount of previously received advance orders to be fulfilled in the subsequent period. Our state transition probability is now represented by $P_{q}\left(\left\{i_{1}, \ldots, i_{M}, b\right\},\left\{i_{1}^{\prime}, \ldots, i_{M}^{\prime}, b^{\prime}\right\}\right)$.

The probability of moving from state $S$ to state $S^{\prime}$ is governed by $\varphi(a), \phi\left(d_{i m m}\right)$, and the choice of $q$ primarily through the following inventory transfer equation for any age class $x$ of interest $(1 \leq x \leq M)$ :

$$
i_{x}^{\prime}= \begin{cases}{\left[i_{x+1}-\left(d_{i m m}+b-\sum_{j=1}^{x} i_{j}\right)^{+}\right]^{+}+q,} & x=a \\ {\left[i_{x+1}-\left(d_{i m m}+b-\sum_{j=1}^{x} i_{j}\right)^{+}\right]^{+},} & x \neq a\end{cases}
$$

where $(\text { value })^{+}$is equivalent to $\max (0$, value $)$. All advance online orders from $\Theta\left(d_{a d v}\right)$ simply become the next state's $b$.

Let matrix $\bar{P}$ represent all elements of $P_{q}\left(S, S^{\prime}\right)$. Principally, each element equals the sum of all possible combinations of $a, d_{i m m}$, and $d_{a d v}$ that moves $S$ to $S^{\prime}$.

$$
P_{q}\left(S, S^{\prime}\right)=\sum_{a} \sum_{d_{i m m}} \sum_{d_{a d v}} \Theta\left(d_{a d v}\right) \cdot \phi\left(d_{i m m}\right) \cdot \varphi(a)
$$

The reward (or cost) of ordering $q$ units while in state $S$ is calculated as expected reward over all possibilities of applicable incoming demand. It is modeled through 5 components, each with respective parameters including: the retail price of the item $p$, the markdown sales given in percent of retail price $s$, a goodwill penalty $g$ for each occurrence of stock-out, the purchase cost of a unit of inventory $c$, and a holding cost per unit per period $h$. We observe an outdating event whenever an inventory unit reaches the end of its freshness life prior to being sold.

Let $I=\sum_{x=1}^{M} i_{x}$, and we have the first component accounting for revenues gained from units sold at retail price.

$$
p \cdot \min \left[d_{i m m},(I-b)^{+}\right]
$$

The second component tracks revenues from units sold at discounted price, and is given by:

$$
(1-s) \cdot p \cdot \min (I, b)
$$

where $p$ denotes retail price of the particular product and $s$ represents the discount given in percent.

Let $g$ stand for the goodwill penalty that results from being unable to fulfill a customer's demand. Essentially, this refers to the loss of reputation when a customer goes through the unpleasant experience of a stock-out.

$$
-g \cdot\left(d_{i m m}+b-I\right)^{+}
$$


When placing replenishment requests, the retailer is billed accordingly based on unit $\operatorname{cost} c$.

$$
-c \cdot q
$$

Holding costs are assessed on all inventory; less any units that are expected to expire or be sold.

$$
-h \cdot\left[I-\max \left(i_{1}, d_{i m m}+b\right)\right]^{+}
$$

We now combine the reward and cost components (numbered equations) to calculate the expected net reward of being in state $S$ and taking action $q$ as:

$$
R_{q}(S)=\sum_{d_{\text {imm }}}[(1)+(2)+(3)+(4)+(5)] \cdot \phi\left(d_{\text {imm }}\right)
$$

For example, when met with 1 unit of immediate demand for the selling period, if the system was in state $\left\{i_{1}=2, i_{2}=1, b=0\right\}$ and $\{q, p, s, g, c, h\}$ were $\{1, \$ 3,0$, $\$ 0, \$ 2, \$ 0.1\}$, then the expected reward would consist of making a sale of 1 unit (\$3), ordering 1 unit (-\$2), and holding 1 unit (-\$0.1) for a resulting period net profit of $\$ 0.9$. Similar to the probability matrix $\bar{P}$, we collectively call all combinations of the expected reward of being in state $S$ and taking action $q, R_{q}(S)$, as elements of the reward matrix $\bar{R}$.

\section{Method \& parameters}

To solve the MDP, we use the open-source R-Studio programming environment (see, rstudio.com) and the $\mathrm{R}$ package MDPtoolbox developed by Chades et al. (2017) [45]. For each experiment, the appropriate transition probability matrix $\bar{P}$ and reward matrix $\bar{R}$ are calculated for all choices of $q$. A relative value iteration algorithm that seeks to maximize the long run expected profit is then applied to solve the following objective function:

$$
f_{n+1}(S):=\max _{q}\left\{\sum_{S^{\prime}} \bar{P}_{q}\left(S, S^{\prime}\right)\left(\bar{R}_{q}\left(S, S^{\prime}\right)+\gamma f_{n}\left(S^{\prime}\right)\right)\right\}
$$

where $n$ is the iteration number $(\max n=1000)$ and $\gamma$ is the discount factor set at 0.9999 .

For demand input, we explore how growing portions of advance orders from online purchases may impact a grocery retailer. A total incoming demand with mean 5 is split into independent proportions of advance and immediate demands, including 0\%:100\%, 20\%:80\%, and 40\%:60\%. For example, a 40\% advance order case will take mean advance demand of 2 units, and mean immediate demand of 3 units as input parameters.
To ensure that we perform a fair comparison of differing demand ratios and allow for tractable state space dimensions in the MDP formulation, we model demand as following a truncated Poisson distribution. The pmf $v_{1}(x)$ with $\operatorname{supp}\left(v_{1}(x)\right)=\{0,1,2,3\}$ is defined as a base demand distribution with mean 1 (Table I), and is calculated according to the optimization:

$$
\min \frac{1}{4} \sum_{x=0}^{3}\left|\operatorname{Poi}(x)-v_{1}(x)\right|
$$

s.t. $\sum_{x=0}^{3} v_{1}(x)=1$, and $\sum_{x=0}^{3} x v_{1}(x)=1$

Table I. Truncated Poisson distribution with mean 1

\begin{tabular}{|c|c|c|c|c|c|c|}
\hline & $\mathbf{x = 0}$ & $\mathbf{x = 1}$ & $\mathbf{x = 2}$ & $\mathbf{x = 3}$ & sum & mean \\
\hline $\operatorname{Poi}(x)$ & 0.368 & 0.368 & 0.184 & 0.061 & 0.981 & 0.919 \\
\hline$v_{1}(x)$ & 0.360 & 0.368 & 0.184 & 0.088 & 1.000 & 1.000 \\
\hline
\end{tabular}

From the base distribution $v_{1}(x)$ we construct demand distributions for means $\{2,3,4,5\}$, namely $v_{2}(x)$ through $v_{5}(x)$, by applying the generic discrete convolution formula below:

$P\left(v_{j+k}(x)=z\right)=\sum_{y} P\left(v_{j}(x)=y\right) \cdot P\left(v_{k}(x)=z-y\right)$

We now have comparable demand distributions as the first input parameter. Also, to better understand the relationship between ADI and supply lead time, online orders can be placed either 1 or 2 days in advance. For simplicity, only one pickup delay duration is offered per each experiment case.

Specific to products with low shelf lives, a maximum age class of $M=3$ days is used for items received from replenishment. To provide a meaningful analysis across the many products in the perishables category, the unit cost of the product to the retailer covers $\$ 1, \$ 5$, and $\$ 10$. These may represent organic soft-skinned fruits (berries, grapes, peaches) as well as ripened avocadoes and various vegetables. Many preservative-free, readyto-eat meals (cooked-meat dishes, sushi platter) that are delivered to the store and cannot be frozen, or specialty baked goods not made in the store's pantry are also represented here. Other freshness-constrained products such as bouquet flowers or Cheesecake Factory-branded desserts fall closer to the higher end of this range.

Since profit varies from product to product, we set the markup at $20 \%, 50 \%$, or $80 \%$ of the cost to retailer [46]. When applicable, the discount to be offered in exchange for the customer's future demand information is given at $5 \%, 10 \%$, and $15 \%$ of the full retail price. For instance, if $c=5$ and markup $=20 \%$, the customer would pay $\$ 5.7$ after $5 \%$ discount. 
Taking into account the unpleasant experience of a stock-out, which may leave the customer with a negative impression, we assign either $\$ 0$ or $\$ 1$ as the goodwill penalty. Note that this penalty is in addition to the loss of revenue from not making the sale. Finally, holding cost is kept constant at $\$ 0.05$ per unit per period. This represents costs from potential mishandling of products; as well as storage and refrigeration requirements.

We conducted 720 experiments based on a full factorial design, less any that are redundant, comprising the parameter choices outlined in Table II. They include a total of 20 cases; each containing experiments with the same portion of advance orders, pickup delay and discount given. Product-specific parameters include the age distribution of supply (at the time of arrival), unit purchase cost, retail markup, and goodwill penalty; for which there are a total of 36 distinctive sets to cover a wide range of perishable products.

Table II. Test parameters for all experiments

\begin{tabular}{|c|c|}
\hline Parameters & Values \\
\hline Advance orders & $0 \% / 20 \% / 40 \%$ \\
\hline Pickup delay & 1 day / 2 days \\
\hline Age dist. of supply $\varphi(a)$ & $(0.2,0.6,0.2) /(0.3,0.4,0.3)$ \\
\hline Unit cost $(c)$ & $\$ 1 / \$ 5 / \$ 10$ \\
\hline Retail markup & $20 \% / 50 \% / 80 \%$ \\
\hline Discount $(s)$ & $0 \% / 5 \% / 10 \% / 15 \%$ \\
\hline Goodwill penalty $(g)$ & $\$ 0 / \$ 1$ \\
\hline
\end{tabular}

The size of the problem is primarily determined by the amount of information each state needs to carry. In our case, this includes the quantity of inventory in each age class, and the number of received advance orders that need to be fulfilled in the subsequent period(s). The $\bar{P}$ matrix of the largest experiment here contains $51,042,215,532$ unique elements. The average runtime for each experiment is approximately 10 minutes with a quad-core i7 processor and 16 gigabytes of memory.

\section{Results \& discussion}

Results are presented in relation to the base case with no advance orders. In the figures, each horizontal category shows the mean, along with the 1 st and 3rd quartiles, of the value of interest for all experiments having the same portion of advance orders and pickup delay. For example, a (20\%, 1day) case indicates that $20 \%$ of orders are placed in advance and will be picked up 1 day later. Two experiment sets (both with unfavorable $p=1.2$ and $g=1$ ) returned unprofitable results at the base case, and are excluded from further analyses. All dotted lines are displayed for ease of comparison and do not imply continuity.
First, we review the changes to average long run expected profit between the study cases (Figure 1). Net profit (or loss) is produced through following the suggested optimal ordering policy; taking into account costs incurred from purchasing, holding inventory, goodwill penalty, and revenues gained from sales. For a meaningful comparison, the outcomes are shown in percentage changes over the base case.

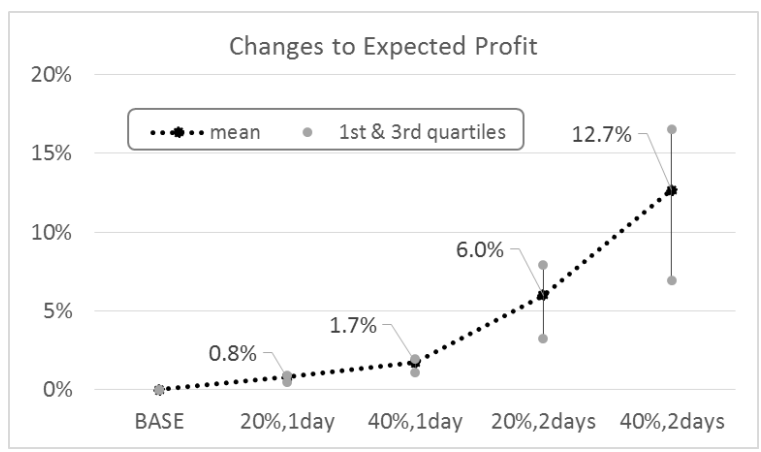

Figure 1. Changes to average long run expected profit

From Figure 1, it is evident that receiving up to $40 \%$ of demand information 1 day in advance proves to offer little benefits to expected profit. Given a 1 day supply lead time, the retailer is only able to adequately accommodate demand that is known more than 1 day in advance. However, when such information is available 2 days prior to fulfillment, profit improves considerably as the known demand portion increases.

We observe a similar improvement trend over the base case in terms of the number of units expected to outdate per day (Figure 2). While receiving orders 1 day in advance produce limited benefits, on average a $26 \%$ reduction to outdating is achieved by knowing $40 \%$ of demand 2 days early. Conceptually, as the amount of orders that are placed in advance by longer than the replenishment lead time approaches $100 \%$, outdating at retail level should reduce to minimal. This fundamental logic is well captured by the slim quartile-deviations from the mean reduction; as marked below in Figure 2.

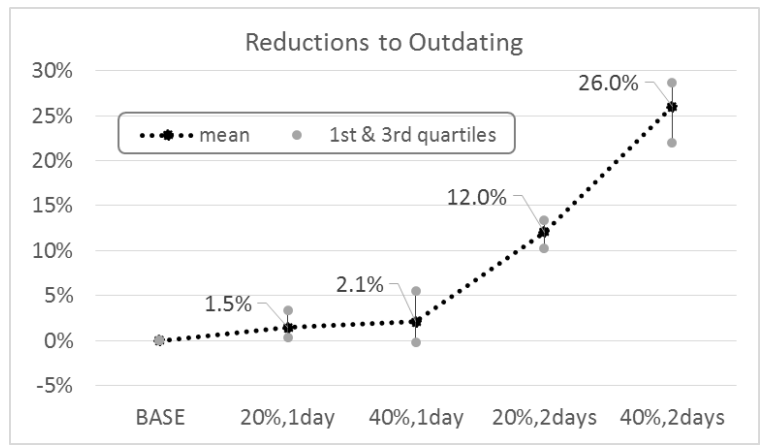

Figure 2. Reductions to average outdating per period 
Considering the amount of perishable groceries sold daily nationwide, these differences could translate to substantial progress in combating the plaguing issue of food wastes within the distribution chain. To understand the underlying cause of why advance orders are able to reduce outdating occurrences, we proceed to examine various inventory metrics in a comprehensive manner.

Recall that in all cases the total incoming demand has a mean of 5 units per period. Figure 3 shows the average stock level and order quantity on the same vertical axis. Each vertical bar signifies the average amount of inventory held across selling periods. Given sufficient time to react, the store is able to slightly increase order sizes as advance order percentage grows.

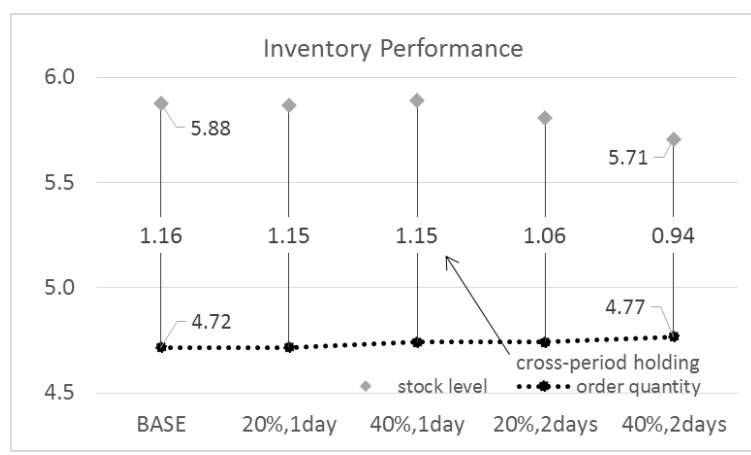

Figure 3. Various inventory performance metrics

At the base case, an average of 0.88 units of inventory are held as safety stocks at the start of every period. When $40 \%$ of the orders are known 2 days in advance, safety stock decreases to 0.71 units; a striking $19.32 \%$ reduction. The difference between mean stock level and mean order quantity is, in fact, the mean daily unsold inventory; which must be held overnight and are potentially subjected to outdating. In effect, when the demand lead time is longer than the supply lead time, the presence of $40 \%$ ADI significantly reduces crossperiod holding from 1.16 to 0.94 units. This also implies that, on average, each unit of inventory spends less time in the grocer's possession. The combined effects of holding less inventory for less amount of time directly impacts the likelihood of having products expire while on hand. And the resulting cost-savings, along with more selling opportunities from larger replenishment quantities, together help improve profit margins. This is another instance where a greener operation can occur alongside a leaner and more profitable operation.

Next, we shift our attention to the implications on customers through a number of service performance metrics. Figure 4 reveals the store's ability to fulfill demand, measured by fill rate, which is calculated from total sales over mean demand. As demand uncertainty decreases, more sales take place overall. Remarkably, not only do advance orders help lower inventory; they also increase the fill rate simultaneously.



Figure 4. Fill rates and availability levels

However, due to prioritizing the fulfillment of any backlogged demand first, the tradeoff consequently leads to a reduction in availability to immediate demand (Figure 4). We define availability as the probability that a given demand will be readily fulfilled, for each respective channel. With more advance demands, customers who need products immediately may face lower availability levels. Without a limit to how much advance orders should be accepted each day, a sudden demand hike today could result in high backlogs that draw on an already-depleted inventory tomorrow.

On the other hand, customers who place advance orders enjoy near-perfect availabilities. As an example, moving from base case to the $(40 \%, 2$ days $)$ case reduces availability from $91.2 \%$ (all customers) to $88.9 \%$ (60\% of customers); whereas customers who placed orders in advance (40\%) will experience a $99.9998 \%$ service level. Note that the 'overall' availability level actually improves when viewing all channels as a whole. The higher availability levels could also be advertised to entice more shoppers to place orders in advance.

Another very important metric for any perishable grocery product is freshness. We learn how the various cases can impact freshness by looking at the remaining lives of products at the time they are sold (Figure 5).

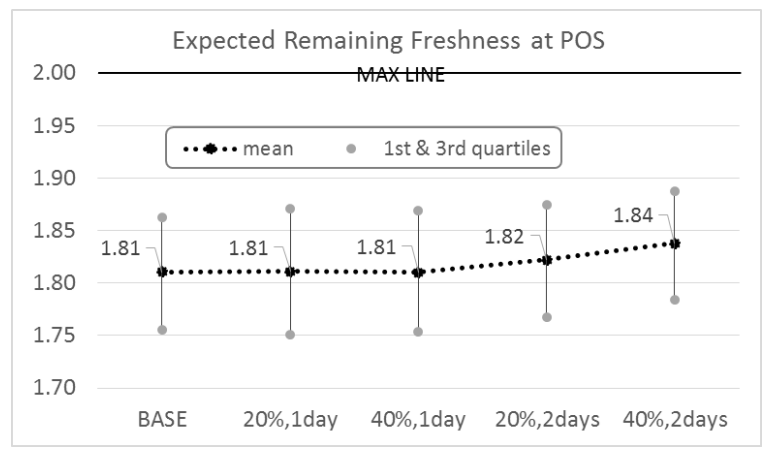

Figure 5. Remaining freshness at the time of purchase 
Replenishments are received with a mean remaining freshness life of 2 days, and continue to deteriorate from there. Figure 5 shows minor improvements in general toward ideal conditions. When $40 \%$ of the orders are placed 2 days in advance, the average deterioration that occurs while the product is at the retail location reduces by up to $15.79 \%$. Essentially, more advance orders lead to holding less left-over inventory over selling periods; thus allowing more customers to purchase newlyreplenished products on the same day they arrive.

Finally, we attempt to answer the question whether retailers could afford to offer any discount to orders placed in advance. We assign markdowns of 5\%, 10\%, and $15 \%$ on the retail price for all advance orders. While these discounts may appear small, they account for large portions of the retailer's profit margin. For example, a particular item that costs $\$ 10$ and retails for $\$ 15$ would be sold at $\$ 14.25$ after 5\% discount; taking 15\% away from the profit the store would have made otherwise. In contrast, to customers who do not mind planning ahead, the price cut could very well be a worthy bonus saving.

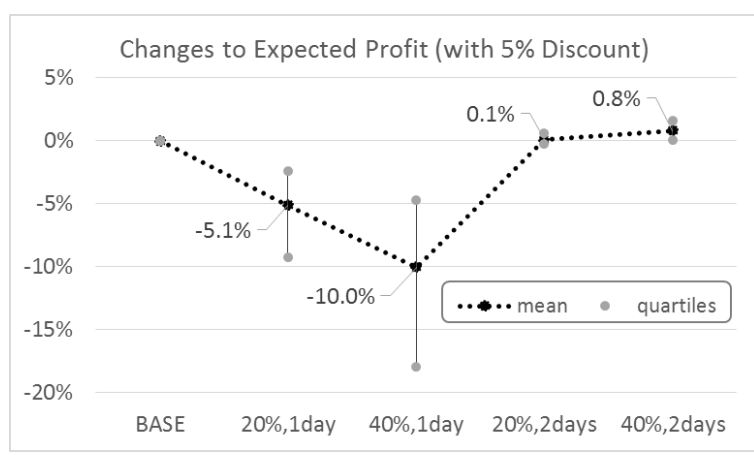

Figure 6. Changes to expected profit with 5\% discount

Since the discount applies to all advance orders, we find that profits are negatively affected when such orders are placed only 1 day in prior to the fulfillment (Figure 6). This occurs even at a low, 5\% discount rate, which aptly exemplifies the challenges faced by grocery retailers. At 15\% discount, the grocer's expected profit could reduce by $23 \%$ on average when $40 \%$ of the orders are placed 2 days in advance; and as much as onethird if the offered pickup delay duration is only 1 day. Thus, care should be taken when deciding how much discount could be feasibly offered by the store in exchange for the customer's demand information.

Other metrics, such as average order quantity or outdating, remain unaffected when offering discount to advance orders. This is because the advance order portions are fixed inputs to the model, and are not dependent on the amount of discount given; as the relationship between the two is not yet clear at this time. Nevertheless, our results indicate that it is possible to 'profitably' offer up to a 5\% discount when the demand lead time is longer than the supply lead time. In such a scenario, both the retailer and the customer fare better economically in the long run.

\section{Conclusion}

We set out to explore how the presence of advance online orders can affect the bottom line of an omnichannel grocery retailer. The goals include finding out if ADI can improve the inventory performance for perishables, and if so, what are the implications on food waste? Given insights into future shelf lives of inventory, how do differing levels of advance orders relate to expected profit, outdating, freshness, and service performance metrics? Could the store afford to offer any discount in exchange for the customer's willingness to place orders 1 or 2 days in advance?

In addition to the previously stated benefits of integrating TTH information in order placing decisions from earlier works, such as Gaukler et al. 2017, we report that more value could be extracted by having better access to ADI and deciding the optimal amount of products to stock [33]. While accepting orders 1 day in advance proves to offer little value, we find that expected profits increase by $12.7 \%$ on average when $40 \%$ of the orders are placed 2 days in advance.

The profit improvement continues to be positive even after giving 5\% discounts to customers, as long as the time window for fulfilment is longer than the replenishment lead time. More importantly, these extra profits do not come at the expense of more wastes; as evidenced by a $26 \%$ reduction in outdating occurrences for the $(40 \%, 2$ days) case when $5 \%$ discounts are given to advance orders (last column of Table III). Table III presents feasible discount percentages that can be offered to customers who place orders in advance; without negatively impacting the grocer's profits. By simply sharing information, customers and retailers can join hands to enhance both their standpoints, while helping the environment at the same time.

Table III. Feasible discounts for various scenarios

\begin{tabular}{|c|c|c|c|c|}
\hline Advance orders & \multicolumn{2}{|c|}{$20 \%$} & \multicolumn{2}{|c|}{$40 \%$} \\
\hline Pickup delay & 1 day & 2 days & 1 day & 2 days \\
\hline Discount given & $\underline{0 \%}$ & $\underline{5 \%}$ & $0 \%$ & $5 \%$ \\
\hline Outdate reduces & $1.5 \%$ & $12 \%$ & $2.1 \%$ & $26 \%$ \\
\hline Profit improves & $0.8 \%$ & $0.1 \%$ & $1.7 \%$ & $0.8 \%$ \\
\hline
\end{tabular}

Though it has been well-documented that ADI can help improve profit or reduce waste, our study appears to be the first to quantify the values of such information in a multi-channel grocery retail setting. Moreover, this 
work reveals the potential impacts of ADI on key contextual metrics, including product freshness and omni-channel service performance. When the demand lead time exceeds the supply lead time, the grocer can expect the amount of cross-period inventory holding to decrease and the overall fill rate to increase in tandem. To a lesser extent, product freshness also improves as more customers place their orders in advance. Thus, Figure 7 summarizes the benefits to each of the three stakeholders, including People, Planet, and Profit:

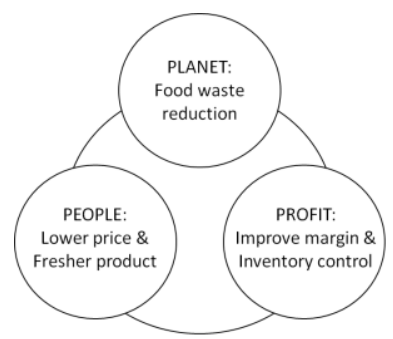

Figure 7. Potential benefits to the triple bottom line

To conclude, our results suggest that physical grocery retailers should embrace the multi-channel trend and consider taking advantage of ADI. We encourage a careful selection of the fulfillment options to manage demand when discounts are involved, as in some cases the price cuts outweigh potential benefits to be gained. When appropriately applied, the additional profits may help expand the breathing room for an industry running mostly on slim margins. Concurrently, retailers can also become more environmentallyconscious by directly contributing to reduce food waste. Future research could be done, for instance, to optimize for parameters other than profit such as freshness, identify incentives that can effectively increase the customer's willingness to order in advance, or explore new ways to manage costs associated with preparing orders for in-store pick up and last-mile delivery.

\section{Acknowledgements}

The authors greatly appreciate the reviewers' time and insightful suggestions to improve this paper. This study was funded by the Center for Supply Chain \& Logistics, Claremont Graduate University.

\section{References}

[1] Goodman, J. (2016). Who does the grocery shopping, and when do they do it? The Time Use Institute. Retrieved from timeuseinstitute.org/Grocery16paper.pdf

[2] Anonymous (2018). 85th Annual report of the grocery industry. Progressive Grocer. April, 2018. p. 30.
[3] Anonymous (2016). Supermarket Facts. Food Marketing Inst. Retrieved from fmi.org/our-research/supermarket-facts

[4] Bloom, J. (2010). American Wasteland. Da Capo Books. ISBN 978-0738215280. p. 166.

[5] Hartman, L. (2016). Manufacturers seeking natural ways to extend foods shelf life. Putman Media. Retrieved from foodprocessing.com/natural-ways-to-extend-shelf-life

[6] Anonymous (2017). RFID is ready to revolutionize the retail industry. National Retail Federation. Retrieved from stores.org/rfid-ready-revolutionize-retail-industry

[7] Myler, L. (2018). Farm-to-table: how blockchain tech will change the way you eat. Forbes Magazine. Retrieved from www.forbes.com/sites/larrymyler/2018/02/16/

[8] Anonymous (2017). The digitally-engaged food shopper. Food Marketing Inst. Product ID 3184. January 2017. p. 12.

[9] Dudlicek, J. (2017). Online grocery growth accelerating. Progressive Grocer. Retrieved from progressivegrocer.com/ online-grocery-growth-accelerating

[10] Anonymous (2017). Connected commerce report. The Nielsen Company. January, 2017. p. 9.

[11] Karaesmen, I. Z., Scheller-Wolf, A., \& Deniz, B. (2011). Managing perishable and aging inventories: Review and future research directions. Planning production and inventories in the extended enterprise, 393-436, Springer.

[12] Nahmias, S. (1977). On ordering perishable inventory when both demand and lifetime are random. Management Science, 24(1), 82-90.

[13] Nahmias, S. (1982). Perishable inventory theory: A review. Operations Research, 30(4), 680-708.

[14] Williams, C. L., \& Patuwo, B. E. (1999). A perishable inventory model with positive order lead times. European Journal of Operational Research, 116(2), 352-373.

[15] Minner, S., \& Transchel, S. (2010). Periodic review inventory-control for perishable products under service-level constraints. OR Spectrum, 32(4), 979-996.

[16] Bakker, M., Riezebos, J., \& Teunter, R. H. (2012). Review of inventory systems with deterioration since 2001. European Journal of Operational Research, 221(2), 275-284.

[17] Amorim, P., Günther, H., \& Almada-Lobo, B. (2012). Multi-objective integrated production and distribution planning of perishable products. International Journal of Production Economics, 138(1), 89-101.

[18] Pahl, J., \& Voß, S. (2014). Integrating deterioration and lifetime constraints in production and supply chain planning: A survey. European Journal of Operational Research, 238(3), 654-674. 
[19] Taoukis, P., Koutsoumanis, K., \& Nychas, G. (1999). Use of time-temperature integrators and predictive modelling for shelf life control of chilled fish under dynamic storage conditions. Intl. Journal of Food Microbiology. 53(1), 21-31.

[20] Nunes, M., Emond, J., Chau K., Rauth, M., Dea, S. \& Pelletier, W. (2005). Effects of in-store conditions on the quality of fresh fruits and vegetables. Research Report for Publix Super Markets. University of Florida.

[21] Chande, A., Dhekane, S., Hemachandra, N., \& Rangaraj, N. (2005). Perishable inventory management and dynamic pricing using RFID technology. Sadhana, 30(2-3), 445-462.

[22] Sahin, E., Zied Babaï, M., Dallery, Y., \& Vaillant, R. (2007). Ensuring supply chain safety through time temperature integrators. The International Journal of Logistics Management, 18(1), 102-124.

[23] Grunow, M., \& Piramuthu, S. (2013). RFID in highly perishable food supply chains-Remaining shelf life to supplant expiry date? International Journal of Production Economics, 146(2), 717-727.

[24] Herbon, A., Levner, E., \& Cheng, T. (2014). Perishable inventory management with dynamic pricing using timetemperature indicators linked to automatic detecting devices. International Journal of Production Economics, 147, 605-613.

[25] Sahin, F., Robinson, P. (2002). Flow coordination and information sharing in supply chains: review, implications, and directions for future research. Decision Sciences, 33(4).

[26] Huang, G., Lau, J., \& Mak, K. (2003). The impacts of sharing production information on supply chain dynamics: A review of the literature. Intl. J. of Production Research, 41(7).

[27] Pierskalla, W. P., \& Roach, C. D. (1972). Optimal issuing policies for perishable inventory. Management Science, 18(11), 603-614.

[28] Puterman, M. (1994). Markov decision processes: Discrete stochastic dynamic programming. John Wiley \& Sons. ISBN 978-0471619772.

[29] Aggoun, L., Benkherouf, L., \& Tadj, L. (1999). A stochastic inventory model with perishable and aging items. International Journal of Stochastic Analysis, 12(1), 23-29.

[30] Kouki, C., Sahin, E., Jemai, Z., \& Dallery, Y. (2010). Periodic review inventory policy for perishables with random lifetime. Proceedings of the 8th Intl. Conference of Modeling and Simulation (MOSIM).

[31] Kouki, C., \& Jouini, O. (2015). On the effect of lifetime variability on the performance of inventory systems. International Journal of Production Economics, 167, 23-34.

[32] Ketzenberg, M., Bloemhof, J., \& Gaukler, G. (2015). Managing perishables with time and temperature history. Production and Operations Management, 24(1), 54-70.
[33] Gaukler, G., Ketzenberg, M., \& Salin, V. (2017). Establishing dynamic expiration dates for perishables: An application of RFID and sensor technology. International Journal of Production Economics, 193, 617-632.

[34] Chua, G., Mokhlesi, R., \& Sainathan, A. (2017). Optimal discounting and replenishment policies for perishable products. Intl. Journal of Production Economics, 186, 8-20.

[35] Adenso-Díaz, B., Lozano, S., \& Palacio, A. (2017). Effects of dynamic pricing of perishable products on revenue and waste. Applied Mathematical Modelling, 45, 148-164.

[36] Buisman, M., Haijema, R., \& Bloemhof-Ruwaard, J. (2017). Discounting and dynamic shelf life to reduce fresh food waste at retailers. Intl. Journal of Production Economics, In press. DOI: https://doi.org/10.1016/j.ijpe.2017.07.016.

[37] Ketzenberg, M., Gaukler, G., \& Salin, V. (2018). Expiration dates and order quantities for perishables. European Journal of Operational Research, 266(2), 569-584.

[38] Hariharan, R., \& Zipkin, P. (1995). Customer-order information, leadtimes, and inventories. Management Science, 41(10), 1599-1607.

[39] Gallego, G., \& Özer, Ö. (2001). Integrating replenishment decisions with advance demand information. Management Science, 47(10), 1344-1360.

[40] Karaesmen, F., Liberopoulos, G., \& Dallery, Y. (2004). The value of advance demand information in production/inventory systems. Annals of Operations Research, 126(1-4), 135-157.

[41] Wang, T., \& Toktay, B. (2008). Inventory management with advance demand information and flexible delivery. Management Science, 54(4), 716-732.

[42] Siawsolit, C., Gaukler, G., \& Seepun, S. (2018). RFIDenabled Management of Highly Perishable Inventory: A Markov Decision Process Approach. Proceedings of the Hawaiian Intl. Conference on System Sciences (HICSS-51).

[43] Anonymous (2018). Food \& beverage consumer trends. Information Resources, Inc. p. 40. Retrieved from iriworldwide.com/en-us/IRI/media/Library/Q1-FB-Trends2018.pdf

[44] Clarke, P. (2017). How an online grocery platform could reshape retail as we know it. Harvard Business Review. Retrieved from hbr.org/sponsored/2017/05/how-an-onlinegrocery-platform-could-reshape-retail-as-we-know-it

[45] Chades, I., Chapron, G., Cros, M., Garcia, F., \& Sabbadin, R. (2017). R Package 'MDPtoolbox'.

[46] Crowe, A. (2011). Biggest grocery store markups: The worst deals in the aisles. Retrieved from aol.com/2011/02/18/biggest-grocery-store-markups 